\title{
Using the Web to Teach Economics
}

Dr Martin Poulter, The Economics Network, University of Bristol, and Dr Douglas Chalmers, Glasgow Caledonian University

1 Introduction

$\begin{array}{ll}1.1 & \text { Online communication } \\ & 2\end{array}$

$\begin{array}{ll}1.2 & \text { Networked learning materials } 3\end{array}$

2 Making, linking and using Web materials 5

$2.1 \quad$ Web site basics 5

2.2 Ready-made sites 6

$\begin{array}{lll}2.3 & \text { Creating more ambitious resources } & 7\end{array}$

2.4 Finding quality economics materials on the Web 8

3 Pitfalls 9

3.1 Linking to external sites 9

$\begin{array}{lll}3.2 & \text { Accessibility issues } & 10\end{array}$

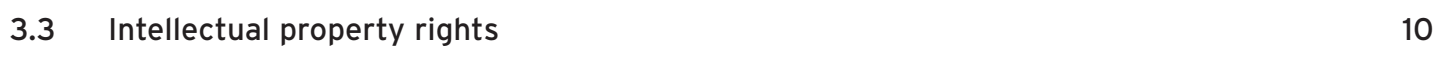

3.4 Student plagiarism 11

4 Designing Web-based activities 12

$\begin{array}{ll}4.1 & \text { The information skills challenge } \\ & 12\end{array}$

4.2 Making the leap from text-based study to Web-based study 13

$\begin{array}{lll}4.3 & \text { 'Economic bricolage' - building an economic case from diverse fragments } & 14\end{array}$

5 Case studies 16

$\begin{array}{ll}5.1 & \text { Using the Web to teach economics: a personal reflection }\end{array}$

$\begin{array}{ll}5.2 & \text { Electronic teaching of economics at a well-resourced institution }\end{array}$

6 Conclusion 20

7 Where next? $\quad 21$

$\begin{array}{ll}7.1 & \text { Suggested reading } \\ 7.2 & 21\end{array}$

$\begin{array}{lll}7.2 & \text { Key Web resources } & 21\end{array}$

Notes $\quad 22$

References $\quad 23$

Glossary $\quad 24$ 


\section{Introduction}

'Today's digital kids think of information and communications technology (ICT) as something akin to oxygen: they expect it, it's what they breathe, and it's how they live.'

Seely Brown (2001)

When Tim Berners-Lee set up the first Web server in 1990, it is unlikely that he realised just how much this would revolutionise not only the world of communication, but also that of teaching and learning. Arguably, prior to the internet, the last technology that so revolutionised the way people sat and talked together was the invention of the table (Shirky, 2003).

Yet one and a half decades on, the (often uncomfortable) reality with which we in the lecturing community have to contend is a culture clash between ourselves and the first online generation that we are now teaching.

Our students frequently text on mobile phones, gossip using instant messaging and access music via online sharing. Hayward et al. (2003) found that 96 per cent of 16-18-year-olds use the internet at least once a month, and 86 per cent consider themselves intermediate, advanced or expert computer users. Although a common misconception of internet activity is that of the lone 'anorak' surfing the net individually, the reality is more often that of the virtual community. Most students will be members of some virtual communities, whether they are simply chat rooms or developed interest groups.

Anecdotally, it increasingly seems that some students aim to get through their early years at university without buying a textbook, relying instead on the internet. Most certainly expect the academic, social and administrative facets of their learning at university to have online aspects that work seamlessly together.

For lecturers, the learning curve for this new technology is much steeper. A small band of adopters have long been using the Web in their teaching, but course websites have only become the norm in the space of the last few years. Many lecturers still find PowerPoint a challenge.

In section 2 of this chapter, we will explore what a course website can do and how you can make one without programming, using just your browser. Then in section 3 we consider some issues, such as disabled students and plagiarism, that warrant particular thought in the context of online learning. Section 4 looks at some specific online activities for economics, while section 5 contains case studies from two other economics lecturers. Our focus in this guide will be on areas where the Web provides a distinctive advantage, namely online communication and rapid access to interactive resources.

\subsection{Online communication}

With increasing student numbers, short semesters and tight budgets, it is increasingly difficult to give students personalised attention. The decline of the tutorial from the teaching process is an illustration. While lectures may remain a staple aspect of modern higher education, weekly or twice-weekly seminars with perhaps 20 students have come to replace the tutorial as the main interaction between the student and the lecturer or tutor. 
The Web can help us to regain that sense of personal guidance and mentorship because with online discussion we can monitor our students' progress and contributions to the class. We can observe and encourage their developing skills, including their ability to think for themselves, to work individually and to contribute to a group.

Leidner and Jarvenpaa (1995) identify four roles that IT can play in the context of education. Kevin Hinde sees his economics website (http://www.kevinhinde.com/) as progressing through these four functions as he gains experience:

- automating the delivery of information to students (for example, Hinde's slide presentations);

- collecting timely feedback on students' responses to the class material (Hinde's site has a feedback form that sends him an e-mail);

- allowing students to share and explore information together, involving them in a process of discovery (Hinde sets 'Web activities' and has online bulletin boards for student discussion);

- devolving authority away from the lecturer, so that he or she can guide the learning process while it occurs in different locations, rates and group sizes (see Hinde (2003) and the case study in section 5.1).

Course websites usually focus on the first of these roles. Yet it is the latter three which can potentially recapture the aforementioned sense of individual contribution to a learning community. Virtual Learning Environments and other tools that we will consider in section 2 are suited for this active learning style with their facility for moderated online discussion.

Online discussion has a number of benefits relevant to the modern university context:

- It allows own time (that is, asynchronous activity). This flexibility is increasingly important for the modern student, who will normally have to juggle study with a part-time job.

- It shares student queries across the group. If students direct questions to you through an online forum (rather than coming to your office), the record of the question and of your answer is visible to the other students. This can be extremely useful in that it allows you to build up a Frequently Asked Questions (FAQs) document with answers.

- It does not require social confidence. Much anecdotal evidence suggests that individuals who are most reticent in a face-to-face seminar, whether through social shyness or lack of confidence with English, can and do contribute successfully in an electronic forum.

- It shifts some costs away from the lecturer. As class sizes grow, the burden of photocopying and distributing handouts is greater, unless handouts and announcements are distributed electronically, when the task of printing them belongs to the student.

This guide will illustrate use of the Web as a complement to existing teaching practice, rather than as a replacement for physical meetings between learners and tutors.

\subsection{Networked learning materials}

In economics, we are often trying to convey mathematical models. In particular, we are concerned with the effect of changing a parameter; how curves shift, how equilibria move, how different kinds of change interact with each other. In a standard lecture, we would usually convey this by building up different coloured lines on a static whiteboard or OHP diagram.

Since long before the Web, computer software and electronic workbooks have enabled students to experiment with models, experiencing them in an immediate and visual way which, at least in principle, allows them to gain a feel for the behaviour of the model, along with their formal understanding. For this software to be used by students, it had to be either paid for or programmed in-house, then made available in the student computer rooms. 
The Web combines that interactivity with immediacy. Rather than putting the ThinkEconomics interactive graphs on our students' computers, for example, we only need to give them the relevant URL (Web address), in this case: http://www.whitenova.com/thinkEconomics/. This is an example of how 'The Web fundamentally alters the cost structure of instruction and learning by changing the costs of authoring, publishing, distributing, modifying, updating, applying, and using economic course materials' (Daniel, 1999).

The material being shared across the Web is not just documents, but interactive resources like self-test quizzes, spreadsheets, animations and complete economic models. Figure 1 shows one of many interactive macro models from Manfred Gärtner's site (Gärtner, 2001). The instructions on the right guide the student through a series of activities. The curves on the graph move in response to student input (http://www.fgn.unisg.ch/eurmacro/tutor/).

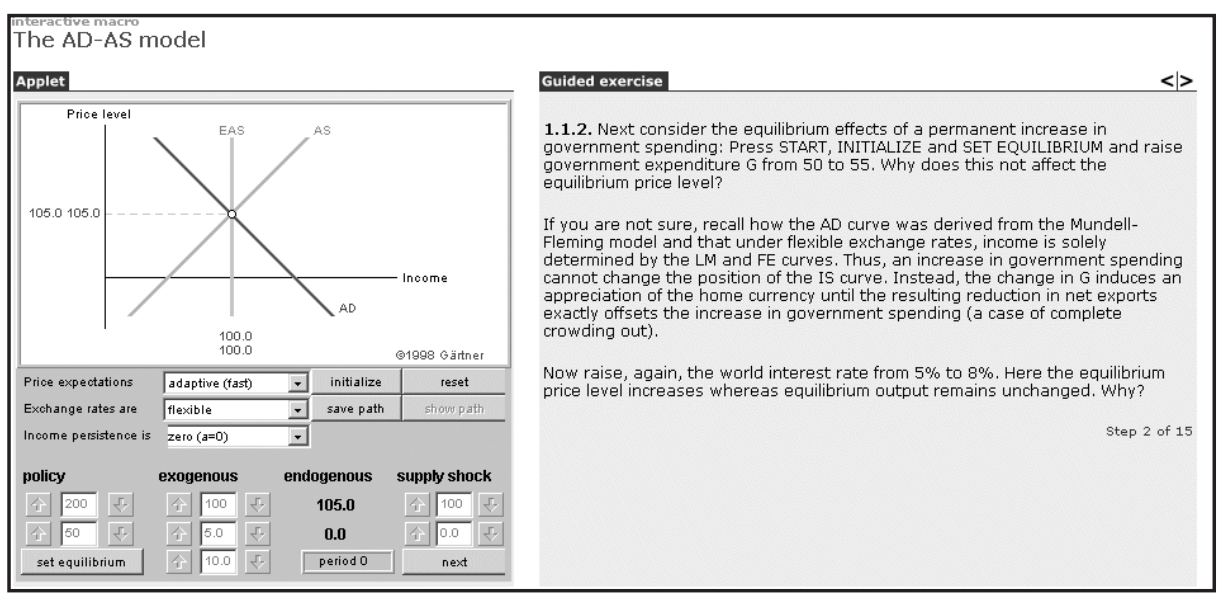

Figure 1. Screenshot from Manfred Gärtner's European macro site

Building on the traditional idea of a reading list, the Web permits the creation of a resource list - a site with links to all these kinds of material. The context of an online discussion board allows students to build the resource list themselves. If you are using a problem-based learning (PBL) approach, you might present students with a research question and then challenge them to contribute relevant sources to a list. The role of the lecturer is to guide this process rather than provide a fully formed list of sources (see the chapter on PBL in this handbook).

Finding useful online materials is a non-trivial task that we will explore in the next two sections. Then in section 4, we will see how online resources can be given a meaningful educational context. 


\section{Making, linking and using Web materials}

\subsection{Website basics}

Figure 2 shows the home page of the course site which has been developed by Frank Stephen and colleagues at Strathclyde University for first-year economics (http://homepages.strath. ac. uk/ hbs97102/econ101/).

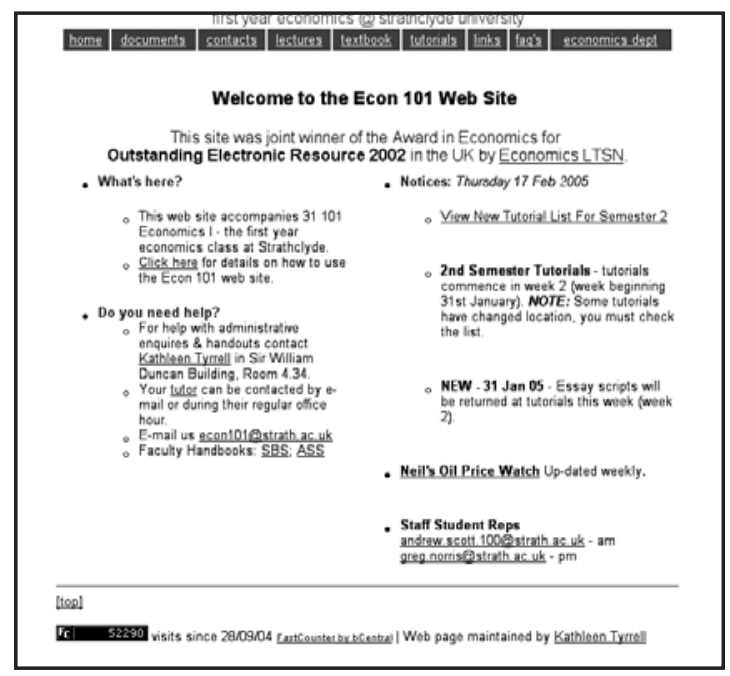

Figure 2. The Strathclyde Econ 101 home page

This uncluttered, readable site is made up of several documents linked from the navigation bar at the top of the page. A wide variety of information is included, some of it administrative, some focused on specific lectures or assignments, including:

- module specification;

- contact details for all staff;

- lecture notes;

- past exam papers;

- course announcements (on the front page);

- links to the institution's study skills guide and faculty handbooks;

- links to key external sources, including the textbook support site.

Some 99 per cent of surveyed students found this site 'useful' and 80 per cent made use of the multiple-choice quizzes on the textbook site, according to a 2002 private communication from colleague Peter McGregor. 
In principle any kind of file can be put online, including spreadsheets, mathematical workbooks, documents and images. Students can download these from their browser and open them using the relevant packages on their own computer. Much of the content of the Strathclyde site is in Word and PDF files, for example. HTML (HyperText Mark-up Language) files glue these all together and encode the site's internal and external links.

These HTML files are essentially structured text files. They can be created with word-processor-like packages such as Macromedia Dreamweaver and Adobe Go Live, which can be purchased at an educational discount, or with many free tools of varying quality. We do not recommend using Microsoft software, such as the 'Save as HTML' feature in Word. The files so created can be many times larger than necessary, and reinforce Microsoft's near-monopoly by working imperfectly with other software.

\subsection{Ready-made sites}

The last few years have seen the mainstream emergence of a few tools that simplify the process of putting text online. Some of these are packages that have to be set up by a system administrator, while others are services running on an external server. Some have to be paid for, but many are open source or otherwise free.

\section{Virtual Learning Environments}

A Virtual Learning Environment (VLE) gives you an instant Web front-end for all your documents, allowing you to post announcements, share documents, create surveys or moderate online discussions. For much more on VLEs, see the dedicated chapter in this Handbook.

\section{Web logs}

A Web log ('blog') is like an online diary. You enter new items (fragments of text, perhaps containing links to other sites) through a form in your Web browser. The software takes care of presenting the entries in an attractive site, as well as archiving them in a date index and/or subject index. Some blogs have a facility for users to comment on new entries. However, if this facility is not protected in some way, it can be abused by spammers. WordPress (see $\mathrm{http} / /$ wordpress.org/) is a popular piece of blogging software which is free, allows passwordprotected posts, can have one or multiple authors and has a comments facility, in which you can moderate comments left by your readers. Alternatively, you can use an external service such as Blogger (see http://www.blogger.com/tour_start.g).

Blogs have proven popular with young people, with recent research in the USA suggesting that 52 per cent of all blogs are created by young people aged 13-16 (see http://news.bbc.co.uk/1/ hi/technology/3774389.stm). They are a medium that many students clearly relate to, and just as importantly, they enable non-technical lecturers to provide an instant response to economic news. Two influential blogs by economics lecturers are Bradford DeLong's Semi-Daily Journal (http://www.j-bradford-delong.net/movable_type/) and EconLog by Arnold Kling (http://econlog. econlib.org/). 


\section{Bulletin boards}

There are several free bulletin board packages, with names like phpBB and YaBB, that have to be installed by a system administrator. You can create discussion boards or polls, and monitor or edit the contributions of individuals. Each discussion appears as a long list, with no branching. These environments are very familiar to young Web users.

\section{Online groups}

Yahoo and MicroSoft Network (MSN) each provide a free 'groups' service (http://groups .yahoo.com/ and http://groups.msn.com/) supported by online advertising. The private site they create for you will include a discussion forum where messages can be received by email or read on the Web, a file-sharing area, a facility to add links and a real-time chat area. These services

TOP

Check whether your chosen textbook has a companion site using the list at http://www.economicsnetwork. ac.uk/books/companions_t.htm Some publishers have online services allowing adopters to create course Web pages. are designed for online 'clubs' rather than for education, but they are a simple alternative if your institution does not provide a VLE.

\section{Wikis}

For the more confident lecturer, and in practice the more advanced students, a wiki may be considered. A wiki is a user-editable Web page. Some allow anyone at all to make edits (for example, the Wikipedia, a collaborative encyclopaedia http://en.wikipedia.org/), whereas some are protected by a password. A group of people can use a wiki to collaborate on authoring a document. Links and formatting can be added to the wiki without any specialist knowledge. For more information see http://c2.com/cgi/wiki?WikiGettingStartedFaq.

The advantage of Web logs and some VLEs is that, due to the friendly interface, these sites are normally in the WYSIWYT category (what you see is what you type - or, indeed, what you upload). They also have the advantage that since the end results are HTML pages (rather than uploaded files), they can be made more accessible by the end user. Most browsers will now allow the person viewing to change the text size, or make it speakable with appropriate software, thus making it more accessible.

\subsection{Creating more ambitious resources}

If you are ambitious in this way about what you want to do with the Web, it is worth checking with your institution (via its learning technology unit or computing service) to see if you have access to programmers, software, facilities or other projects that will help.

Ken Heather at the University of Portsmouth benefited from the fact that his institution has a Media Development Group which helped him to create video lectures for the Web (Heather, 2001). Other institutions have dedicated projects for advanced Web authoring, such as online assessment.

It may be possible to have a programmer create one reusable template rather than a whole site. Geraint Johnes at Lancaster, for example, has a series of multiple-choice self-tests on his site (http://www.lancs.ac.uk/people/ecagj/quizzes1.html), as shown in Figure 3. These have been created by taking a general-purpose question template and pasting in text with a text editor. One such template is given in Judge (1999). Similar interactive questions can be created using the Toolbox service (http://www.economicsnetwork.ac.uk/teaching/toolbox.htm), then added to your own site using the 'File/Save As' feature in your browser. 


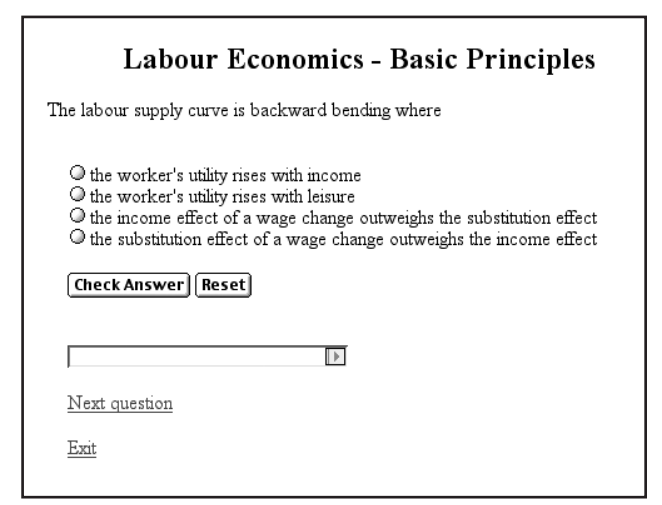

Figure 3 A simple self-test question with immediate feedback

\subsection{Finding quality economics materials on the Web}

Creating a course Web page will usually involve making links to external sites. In the next few sections we will look at issues connected to linking, starting with the question of how to find useful content. There are some dedicated projects that seek out the most relevant sites for economics teaching or research and categorise them helpfully. By using these before trying general search engines, you can save time.

- For learning and teaching materials specifically, there is the Economics Network links database (http://www.economicsnetwork.ac.uk/links/), which is the largest online links database specifically aimed at economics higher education.

- A search for economics on MERLOT (Multimedia Educational Resource for Learning and Online Teaching, a US-based gateway) (http://www.merlot.org/artifact/BrowseArtifacts. po? catcode $=353 \&$ browsecat $=339$ ) brings up many tutorials, lesson plans and other materials, along with users' reviews and comments.

- Resources For Economists is a very comprehensive guide, covering not just teaching resources but every other kind of link that an economist might need. The UK copy is at http:// netec.mcc.ac.uk/EconFAQ.html

- The Bized catalogue (http://catalogue.bized.ac.uk/) is a UK-based source of thousands of economics and business studies links, searchable and browsable by specific topic. Importantly, Bized offers a mailing list informing users of weekly updates on the website, which it is well worth investigating (see http://www.jiscmail.ac.uk/lists/bized-newsletter. html).

For information on how economics lecturers or students may learn to evaluate the worth of materials they find on the Web (including guides to how material should be referenced), you may wish to consult an interactive tutorial called the Internet Economist (http://www.vts.rdn. ac.uk/tutorial/interneteconomist). 


\section{Pitfalls}

Whereas the challenge with a printed handout is to get students to follow up all the recommended reading, a Web page is always a few clicks away from materials over which the author has no direct control. The challenge instead is to have students focus on the most relevant and respectable sources. Another difference is that the visual appearance of a Web page is not under the control of the author but depends on what is used to read it, which might be a computer-room PC, a wide-screen laptop or a mobile phone.

In this section, we consider some consequences of these differences for teaching practice, in particular the proper use and maintenance of external links, catering for disabled users, using others' intellectual property and discouraging student plagiarism.

\subsection{Linking to external sites}

The EDNER Project (2002a) has highlighted some issues that may undermine the value of a set of links for students. One of these is a lack of context: arranging links in one big list is much less useful than indicating how each link is relevant to the students' learning. Giving links a context might be a matter of giving an informative heading, or of presenting links in the context of a specific assignment rather than a general list.

In the case of a library catalogue or local software archive, access to a page might be restricted to your institution, so that someone accessing the site from outside - say, through a commercial service provider at home - will get an error message. If this is the case, it is important to make sure that students know this.

One way in which Web links differ from references in a paper publication is that a reference will always refer to the same thing, but the file that is at a Web address might change at any point in the future. Over time, any list of links will suffer 'linkrot' as files are moved and sites disappear entirely. Linkrot is a large factor in users' frustration with the Web. If you do not keep tabs on linkrot, you might assure students that information crucial to a particular assignment is linked from your Web site when in fact the link only gives an error.

Fortunately, there are two kinds of tool which make it easy to battle linkrot. The first is linkchecking software or online services. You feed this service the home page URL of your site and it checks all the links on all pages, reporting on which are broken. An example is Xenu's Link Sleuth (http://home.snafu.de/tilman/xenulink.html), a program freely available for Windows. For Apple Macs, try Link Checker (http://www.dotsw.com/linkchecker.html).

The other kind of tool is an archiving service. If one of your links is broken because the original owner has taken down that information, the pages may still be available in an archive. Go to the Wayback Machine (http://www.archive.org/) and type in the (now broken) URL. You should now be able to browse a list of archived versions of that page. If the content you want is there, you can replace the broken URL with the URL of the archived site. This will work for many documents, although sometimes not for pages that are deep inside a site, and not for dynamic services such as some interactive quizzes. Alternatively, if you fear that the site will disappear completely in the near future, you may wish to copy the page to your PC and put it up on your own site (see the points on intellectual property below, however). 


\subsection{Accessibility issues}

A site is accessible to the extent that different categories of user can make use of it. Users might be prevented from using a Web resource by a disability such as colour-blindness or motor impairment, by the type of equipment they are using (for example, a palmtop rather than desktop computer) or even by having a slow modem, which effectively rules out downloading large files. A guide entitled 'Web accessibility issues for higher and further education' (EDNER Project, 2002b) lists the categories of user for whom there might be access problems. Accessibility has become a more important issue in the UK with the advent of legislation (the Special Educational Needs and Disability Act 2001) that compels universities to give disabled students the same access to online resources as is given to other students.

A truly accessible page is readable in unusual contexts, such as on audio browsers and palmtop computers. The good news is that the simpler and more structured the pages you create, the more likely they are to be accessible.

The bad news about accessibility is that the more adventurous you are in terms of putting interactive or audio-visual material online, the more work you have to do to make it accessible. If you have audio lectures, your site discriminates against deaf students unless you also supply a transcript, or at least a summary that would help them decide whether to use a transcription service.

Remember that a student with the wrong software is, in effect, a disabled student. If a certain piece of content such as an online video is crucial for an assignment, you need to check that the appropriate plug-in exists and is installed on students' computers, or is available for them to install.

The Making Connections Unit (http://www.mcu.org.uk/) has many specific articles on accessibility issues. Poulter (1999) is an overview article. An additional central resource on the accessibility of Web resources, giving many simple tips, is the Web Accessibility Initiative (2003).

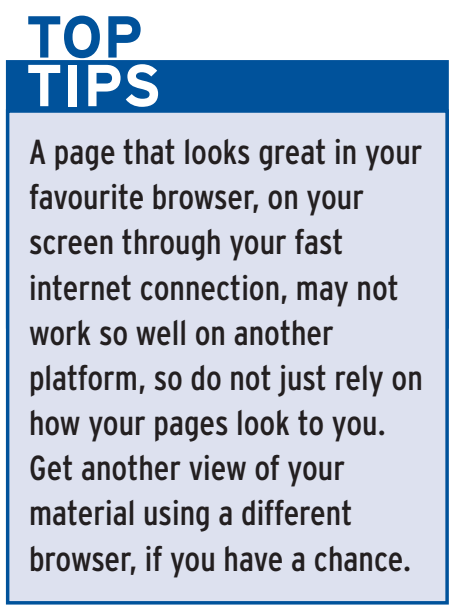

\subsection{Intellectual property rights}

Although we cannot give legal advice, it is appropriate to take a look at issues connected to ownership of material on the Web. The internet has become synonymous with copyright violation, partly because of the huge volume of music and video that is being traded. Some online copyright violations are nonetheless tolerated for the common good: an example is the fact that the Google search engine makes a copy of every page it encounters.

However, the law applies to electronic materials as much as to paper materials, so just because it is technically possible for you to print out an online book chapter for all your students, you are not within your rights to do so unless you have permission of the copyright holder. In other words, material on public access (an internet term) is not necessarily in the public domain (a legal term).

As with other instances of copyright, you as a reader have 'fair dealing' rights that allow you to quote extracts from other works for purposes of research, criticism and reporting on current events. You can also make copies for your own personal use. Incorporating an online resource into a lecture presentation would be covered by this exemption, but printing out someone else's document for each of your students would not. Giving students the Web address of a document is, of course, allowable.

Copyright law allows special exceptions for educational institutions. For instance, 'Anything done for the purpose of setting or answering examination questions' is exempt from copyright, 
according to the UK government's intellectual property gateway (http://www.intellectualproperty.gov.uk/std/faq/copyright/ex_education.htm).

\subsection{Student plagiarism}

A downside of the ease of access provided by the Web is the great ease with which students can plagiarise existing material. Feeding this temptation are a spate of so-called 'research assistance' essay banks. Students donate or sell their essays to a bank, along with feedback they were given by their tutors. Other students can then browse through these to find an essay similar to what they are working on and pay a small fee to download it. Each site may have several hundred essays specifically on economics, although many are of such poor quality that students have little to gain by submitting them. Figure 4 shows some of the economics content offered by Coursework.info, which invites users to 'invest in [their] education' by paying to download the essays. Similar sites are listed by the JISC Plagiarism Advisory Service (http://www.jiscpas. ac.uk/site/res_essay.asp).

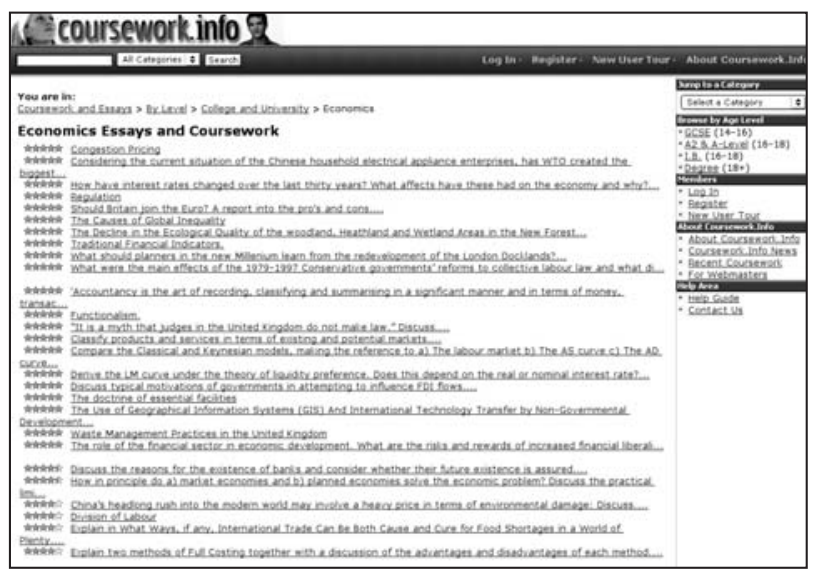

Figure 4. Essays on offer from Coursework.info

Chizmar and Walbert (1999) advise that plagiarism 'has led some tutors to discourage the use of Web sources. An alternative, however, is to change the nature of assignments to make cutting and pasting a virtue, and to teach critical use of the Web.'

As with student plagiarism generally, various kinds of counter-measure can be taken (see Kerkvliet and Sigmund (1999) for an analysis of the effectiveness of various measures). We can make sure students understand the definition of plagiarism and the severity of its consequences. We can set essay titles that are novel or specific, or that refer to current events (see the Plagiarism chapter of this handbook). What we cannot reasonably do is check all the online sources from which a suspicious essay might have come. Fortunately, the technology can help, in the form of the JISC Plagiarism Detection Service (http://www.submit.ac.uk/), which is available to many UK higher education institutions.

This service is quite quick to use after the initial investment of time to register a class and list the students. Students can then submit directly to the software via a URL that you provide, or you can upload a document yourself. The service displays an originality report, colour-coding passages that are similar, in a slightly fuzzy sense, to text from the Web, from subscription services and from other students' submissions. 


\section{Designing Web-based activities}

\subsection{The information skills challenge}

Traditionally, a student working on an essay would have had recourse to a library and perhaps inter-library loans. Now, in addition to the traditional non-digital library, there is a large and increasing range of resources; not just electronic forms of primary texts, but also interactive tutorials and online economic models. Whereas the traditional library is managed by librarians, the Web is relatively anarchic. There is no guarantee of academic status, objectivity or educational appropriateness in the results of a Google search. Chizmar and Walbert (1999) warn that fruitless Web searching may detract from study time and conclude, 'the prudent strategy might be to plan a modest increase in Web use as part of a well-balanced learning program'.

Box 1 shows what can happen when students search indiscriminately for economics terms. Looking in a variety of economics glossaries, we found that explanations of a term differ not only in length and amount of context, but on questions of emphasis and meaning. 'Deflation' was usually defined in terms of prices, but one definition does not mention prices. Definitions of 'unemployment' disagreed on whether it was a number or a state, and on what could be unemployed. The ease with which multiple, potentially confusing explanations can be found makes it advisable to refer students to chosen resources rather than asking them to 'look on the Web'.

Then again, the fact that this plethora of resources has no quality control means that both students and lecturers need a new skill - of identifying relevant, appropriate material. Lecturers should check that material they recommend is suitable for their students and their educational style. This is a transferable skill and part of critical thinking. Students, from their formative university years, also need to work towards the skill of quality appraisal of Web-based material.

\section{Box 1. Contrasting definitions of economic terms from the Web}

\section{Deflation}

'Deflation occurs when prices are declining over time. This is the opposite of inflation; when the inflation rate (by some measure) is negative, the economy is in a deflationary period.'

About.com (http://economics.about.com/cs/econometrics///blglossary.htm)

'A reduction in national income and output.'

Bized (http://www.bized.ac.uk/glossary/econglos.htm)

'A fall in the general level of prices. Unlikely unless the rate of inflation is already low, it may then be due either to a surge in productivity or, less favorably, to a recession.'

(Deardorff's Glossary of International Economics:

http://www-personal.umich.edu/ alandear/glossary/)

'The opposite of inflation - that is, a sustained fall over time in the general level of prices, normally measured by the annual percentage increases or decreases of a weighted index of prices of some large and representative sample of goods and services (both consumers' goods and producers' goods) regularly traded in the particular economy under 
consideration. Just as very large scale inflations are normally the result of large percentage increases in the money stock, large-scale deflations are normally the consequence of substantial reductions in the available money stock.'

Glossary of Political Economy Terms (http://www.auburn.edu/ johnspm/gloss/)

\section{Unemployment}

'The difference between the number of people in the labor force and those working for pay.' Digital Economist (http://www.digitaleconomist.com/glossary_macro.html)

'The non-utilization of labour resources; the condition in which members of the labour force are without jobs. Sometimes used more broadly to refer to the waste of resources when the economy is operating at less than its full potential."

Glossary for a Course in Basic Economics (http://www.chass.utoronto.ca/ reak/glosslist.htm)

'The state of an individual looking for a paying job but not having one. Does not include full-time students, the retired, children, or those not actively looking for a paying job.'

Glossary of Research Economics (http://econterms.com/)

'The unemployment rate is the percentage of the population who are willing to work for the current market wage for someone of his or her skill level but cannot find employment.'

About.com (http://economics.about.com/cs/econometrics/l/blglossary.htm)

Today's resource list is conceptually a cross searcher, locating digital and non-digital objects (abstract, textual, visual, musical, social, multimedia) using different kinds of finding aid (a term from the pre-digital world!). A catalogue is one finding aid. A bibliography is another. Internet search engines are increasingly gaining importance as finding aids, simply because of their immediacy.

Hence there is an extra skills burden for students, in terms of both technology and critical thinking, if they are to become users of online sources. One might view this as an extra burden on the curriculum, but we view it more positively. At a time when degree courses are under pressure to show evidence of transferable skills, the fact that a course includes internet information skills may be a positive selling-point. You might introduce these skills in dedicated sessions for freshers: for example, by getting students to work through the Internet Economist tutorial (http://www.vts.rdn.ac.uk/tutorial/interneteconomist/) or its associated exercises (Poulter and Mitchell, 2001). Alternatively, you can set online activities which teach technology skills, information skills and economic content at the same time, as we show below.

\subsection{Making the leap from text-based study to Web-based study}

In the core first-year economics module at Glasgow Caledonian University, students are assessed through classwork (presentations), an essay and an unseen exam. Under the general class heading of 'presentations', students investigate topics and present their findings, resulting in class discussion and comments from the tutor. This allows a report to be written up which is subsequently marked. We use the first (common) presentation (which, unlike the others, does not involve a follow-up written report) as a method of encouraging group work, introducing students to academic use of the Web, and hopefully illustrating common pitfalls to avoid in their study. 
Essentially the presentation is a 'dry run' that all students have to undertake in week 4, the week before the 'real' presentation programme starts. Students are allocated into groups of three or four - the groups they will stay in throughout the rest of the module and subsequently do their 'real' presentation in. They are all directed to undertake this first presentation, details of which are available only on the divisional website, the URL of which is given in their paperbased module guide. This forces students to find and use the Web-based resources we have provided.

The core of the presentation (found at http://cbs3.gcal.ac.uk/eco/website/EME/EME presentation1a.html) is to find 'robust' economic data about a topic - in this instance, Lone Parents and Poverty in Scotland. Students are asked to do this via the university route: that is, using our recommended online gateways, such as those found on the divisional website or those found on the university library website. Additionally, they are asked to undertake the same task via the different 'route' of using any standard internet search engine. Within this task they are specifically asked to visit a named site that we as lecturers know is out of date and quite 'ropey' (but the drawbacks of this site are not flagged up to the students).

In their presentation to the rest of the class, each group has to give their evaluation as to which is the best 'route' to finding material, and why, and which are the best sites and worst sites they have found (here we would hope they make a critical assessment of the inferior site mentioned above). As individuals they must also e-mail a message to the seminar class bulletin board explaining their choice of best site, and why (as 'economists') they have made this judgement. This also forces them to find the bulletin board and use it! Specifically, the responsibility is on the individual student to do this, not the group. We hope by this to help students to proceed from the linking and lurking stage - reading others' contributions - and to enter into the contributing stage, where they are getting experience in hands-on involvement themselves. Finally, they have to properly reference all the sites they mention.

The resultant presentations on this topic are made by each group to the rest of their colleagues in successive 5-minute slots, with the rest of the class asked to 'rate' the best presentations informally.

This approach has been found invaluable for several reasons. Firstly, it is quite informal because it is not officially marked, thus helping to calm students' nerves. It also allows class members to see how a tutor would distinguish a good presentation from a bad one. Secondly, it illustrates several very useful issues. For instance, we invariably find that a large minority of groups do not read the question properly. There are always some who come with a presentation on the topic of lone parents, rather than on 'How to find information in the most robust manner about a topic on the Web - in this case, lone parents'. Many only carry out part of the presentation: perhaps they do not post the message, or they only use one route, or they obviously have not visited the links suggested to them regarding how to reference online sources properly.

The approach is therefore very useful in showing how a presentation may suffer from carelessness and lack of attention. We have found that this is invaluable, as it is done in an informal manner, but students are made well aware of how they might have lost badly if it had been a summative assignment. It also allows the tutor to summarise what will be key issues, such as the proper manner of evaluating and referencing online resources.

\section{3 'Economic bricolage' - building an economic case from diverse fragments}

Subsequent to student groups undertaking the 'mock' presentation above, they then move on to class presentations that illustrate economic theory through the use of real case studies. One example is using the current shortage of staff car parking spaces at Glasgow Caledonian to illustrate demand and supply. (See http://cbs3.gcal.ac.uk/eco/website/EME/EMECarParkProject.html). 
Essentially, there are approximately 100 places for 1,500 staff, with a campus-wide ballot for permits which, if successfully obtained, cost approximately $£ 600$.

On choosing this topic, the student group is asked to construct a market diagram using figures supplied on the university website above. These figures indicate the number of spaces, the approximate number of staff, the ballot details and price, and also refer to actual questionnaire responses from staff detailing facts such as the maximum price they would be willing to pay to use the car park. The figures (with a little thought) allow them to construct relevant demand curves by constructing the points at which the demand curve would cross each axis. The question is very contemporary given the on-going construction work at the university, of which the students are very much aware. This has cut the number of spaces available for parking, which allows us to ask the students to construct two scenarios: 'before construction work' and 'now'. The issue of the supply curve is also challenging, given that it is totally inelastic in both snapshots, requiring thoughtful interpretation of textbooks which often illustrate only upwardsloping examples.

Once students have constructed the necessary diagrams, they are asked to consider the effect of external changes such as the imposition of congestion charges. They are also asked to consider the issue of 'scarcity' in a broader context by looking at questions of opportunity cost and also alternative uses of the car parking spaces.

Among the websites referenced are those of neighbouring car parks, the local bus companies, a 'sustainable transport site' and Friends of the Earth Scotland. They are, of course, asked to make use of the theory in their economic textbook. Finally, a short tongue-in-cheek video (3 minutes) made by economics staff, looking at congestion, is also made available on disc or downloadable from the Web. This mixture of paper, up-to-date internet and multimedia resources has proven in practice to be very popular with the students. A series of similar presentations forms part of every student's 'coursework' element, the follow-up written report of which is formally assessed. Student reactions from the reports are shown in Figure 5.

\section{Extract 1}

'In our presentation, we got the figures correct for demand but the supply curve was impossible until we discussed a totally inelastic one in class. The books don't always cover all the examples from real life, so you have to think.'

\section{Extract 2}

'The Friends of the Earth website made it clear that our car park was not necessary since we had many alternatives available. The opportunity cost of the car park could have been green spaces in the university to allow the students to de-stress. This would allow rich lecturers to de-stress as well, as they wouldn't have to worry about the cost of running expensive cars.'

\section{Extract 3}

'The hardest bit of the presentation was explaining what happened when the university fixed the price for entry. This meant that there wasn't a market equilibrium. It had been fixed by the authorities.'

Figure 5 Extracts from written group reports 


\section{Case studies}

\subsection{Case study 1: Using the Web to teach economics: a personal reflection Kevin Hinde, Senior Lecturer in Economics, University of Northumbria}

kevin.hinde@unn.ac.uk

I started using the Web in 1996, largely as a means of providing unit outlines and reading lists for the courses I taught. My early rationale was that it might cut down on the numbers who used to knock on my door to ask for a spare handout. However, my strategy as to how the Web can be applied in the teaching and learning of economics has evolved and, indeed, is evolving. All units that I currently teach are supported by a dedicated website, www.kevinhinde.com, a domain name I purchased because it was easier for students to remember than www.unn.ac.uk/ regkh1.

The updated rationale for this more substantive site is based on pragmatism and pedagogy. Higher education in the UK, as we all know, has changed dramatically in recent times. The unitised curriculum presents limited learning time and numerous assessments for our students. Many on-campus learners face financial hardships that force them to work and the rapidly growing cohort of part-time students are usually juggling career aspirations with family and work commitments. Managing the learning process can therefore be difficult for many students.

One aim of the website is to provide a valued 'desktop' information resource for students who follow my courses. To this end there is a Pop-Up Notice Board for each unit that gives details on a weekly basis of what is going on in classrooms and what is expected of students. This facilitates transparency for the individual, particularly if they are immersed in a large year group, and for teaching teams. There are also opportunities for students to access key articles electronically from the library or the Web, and students can even buy the course textbook online.

Another aim is to provide a visually appealing learning medium that enhances the student educational experience, and certainly developments in Web software have facilitated this. One of my early ventures was the initiation of an interactive textbook, although, as with most who use the Web, there are also the obligatory plethora of notes and slides. A recent innovation is the use of slides with streaming audio. Students enjoy the opportunity to pause and rewind an audio slide show and I am considering using it as an occasional substitute for one or two lectures. I have experimented with video, but our university does not currently have the technical infrastructure to support such a development. Moreover, there are still internet traffic problems associated with video, which mean that their effective use is still restricted to wide bandwidths. For the moment I am using slides with streaming audio as a compromise.

Figure 6 shows the links related to one lecture from 'The Economics of Competition'. The lecture title is linked to downloadable lecture notes, and a slide show with audio is also provided. The 'Web Activity' in the second column includes online sources and research tasks. A self-test multiple-choice exercise within an online textbook has been linked directly, and the 'Doing Business' site is an interactive database of the cost of regulation in different countries. The course reading list is linked from elsewhere on the page. 


\section{Lectures}

\section{Introduction to Competition and Regulation}

You will also benefit from listening to the following streaming audio slide shows:

Introduction to Regulation: its significance and rationale. (35 minutes)

\section{Directed Reading}

Chapter 1 of Study Booklet (see below)

Baldwin and Cave Chapters 1 and 10

Cusack J. L. and Hahn R. W. (2003)

The costs and benefits of regulation.

Implications for developing nations, OECD, Paris

OECD (2001) OECD Report on

Regulatory Reform. A summary, OECD, Paris

OECD (2003) Proceedings of Regulatory Issues and the Doha development Agenda. Issues Paper, OECD, Paris

\section{Seminar/Web Activities}

\section{Web Activity: Introducing Competition}

Introductory Multiple Choice Exercise from Roger McCain's website.

An interesting link is provided by the World Bank's 'Doing Business' website. Click here to compare how differences in regulations between countries may affect investment.

Figure 6 References for one lecture from www.kevinhinde.com

The website is now integral to teaching and learning for the units that I teach. I run computerbased workshops alongside lectures and seminars. There are Web-based group activities in which students work on case studies, such as National Lottery regulation, and e-mail their findings to me. I then provide feedback on their work and email a reply before the next session.

Figure 7 shows an example of an activity in which online and paper reading recommendations are combined with advice on online search strategy. Such cases usually form the basis of a future exam question. There are also formative online multiple-choice-style assessments, usually with diagrams and providing extensive feedback, which prepare students for short summative assessments half way through the semester. Students can also reflect on the learning process via an electronic evaluation form and an online Guest Book. So far the feedback has been, on the whole, very positive.

There have been two major drawbacks in putting together these Web pages - the time constraint and the lack of cutting-edge technical support. Both cause immense frustrations on occasion, but obviously I believe that the learning benefits outweigh the personal costs of such a project. Many universities have now invested in Virtual Learning Environment (VLE) software packages such as Blackboard, WebCT and so on. This will make the initial construction of electronic courses much simpler for lecturers. However, let me finish with two concerns about the use of VLEs for teaching and learning, at least as they currently stand. First, you will be constrained by the platform design as to what you can do. Changes to the platform design are extremely limited and developing more sophisticated visual presentations will still require time and technical support. Second, whilst each of these platforms has an online community where teachers can share ideas, you will be extremely lucky to view the original site because 
universities are unlikely to allow passwords to outside users. Thus the sharing of ideas is probably going to be stifled by corporate bodies that want to retain control over intellectual property. By contrast, kevinhinde.com is in the public domain and everyone who wants to gets a chance to see it - warts and all!

\section{Some questions on core competences}

1. What is meant by the phrase 'core business'? Why is it important to identify this?

2. What is meant by the phrase 'core competence'?

3. List the features that might constitute core competence in an organisation. Explain why they are 'core competences' rather than say a 'threshold competence'.

Put your answers on the eLearning Forum.

\section{Some online papers on core competences}

Rob Cross, Andrew Parker and Stephen P. Borgatti (2003) A bird's-eye view: Using social network analysis to improve knowledge creation and sharing, IBM Institute for Knowledge-Based Organizations, available from http://www-1.ibm.com/services/files/ ibv_sna.pdf

Robert B. Tucker (2003) Innovation: Core Competency for the 21st Century, The Innovation Resource Group, available from http://www.innovationresource.com/ articles/article_files/core_competency.htm

Kay, J. (1993) The Structure of Strategy, Business Strategy Review

You should also search the Web to find answers to these questions. Use Google, AlltheWeb or some other Search Engine. You might want to go to Brint.com and search for 'Prahalad and Hamel' and 'Tacit Knowledge', 'Business Process Reengineering' and 'Best Practices'.

You should also read Johnson and Scholes (2002) Exploring Corporate Strategy, Pearson Education, London, Chapter 4 or go to the Web-based resource for this chapter of $\mathrm{J} \& \mathrm{~S}$.

Figure 7 A Web activity from www.kevinhinde.com

There have been two major drawbacks in putting together these Web pages - the time constraint and the lack of cutting-edge technical support. Both cause immense frustrations on occasion, but obviously I believe that the learning benefits outweigh the personal costs of such a project. Many universities have now invested in Virtual Learning Environment (VLE) software packages such as Blackboard, WebCT and so on. This will make the initial construction of electronic courses much simpler for lecturers. However, let me finish with two concerns about the use of VLEs for teaching and learning, at least as they currently stand. First, you will be constrained by the platform design as to what you can do. Changes to the platform design are extremely limited and developing more sophisticated visual presentations will still require time and technical support. Second, whilst each of these platforms has an online community where teachers can share ideas, you will be extremely lucky to view the original site because universities are unlikely to allow passwords to outside users. Thus the sharing of ideas is probably going to be stifled by corporate bodies that want to retain control over intellectual property. By contrast, kevinhinde.com is in the public domain and everyone who wants to gets a chance to see it - warts and all! 


\subsection{Case study 2: Electronic teaching of economics at a well-resourced institution \\ Dr Mary Perkins, Howard University, Washington DC, USA}

drmkperkins@hotmail.com

I have been using the Web in economics courses (Principles of Economics (Macro), Introduction to Macroeconomics, International Economics, International Commercial Trade Policy, and Economic Development and Planning) for 8 years. Many of these courses have more than 100 students each semester. I have also trained and advised other faculty, in economics and other disciplines, in the use of the Web.

My intentions in introducing the Web into my economics courses were:

- to provide improved course content via links to the vast universe of economics material on the Web;

- to encourage student interaction through the development of an online community;

- to enhance (and to some extent replace) chalk-and-talk lectures with advanced multimedia presentations;

- to provide student access to interactive learning environments that have proven more effective in imparting economics knowledge;

- to make course administration easier by integrating quizzes, tests, grading applications, course syllabi, calendars and announcements into a single online platform.

An important decision I faced early on involved the selection of a textbook with good Web support. Major economics textbooks are accompanied by a website and in some cases the publishers provide specialised Web development and course management software. In addition, some publishers provide an economics-specific online learning site as well. For Principles of Economics courses, I chose McConnell and Brue (2001), which is integrated with Pageout (http://www.pageout.net/page.dyn/intro/welcome/), template-driven course management software that can be used to build a customised course website. The publishers, McGraw-Hill, even provide Web hosting at no cost to the user. The text website contains tutorials (interactive and otherwise), graphing kits, chapter-by-chapter PowerPoint slides, links to economic websites and current economic event sites, videos (streaming and VHS), 'contact the author' sections, career centres, bulletin boards, etc. Students have access to my Principles of Economics course website, which is integrated with the text website and the online learning website.

Implementation has been easier due to the level of support received from the university. In addition to training and teaching assistants, I have been able to offer most of my Web-enhanced economics courses in 'smart rooms'. The intelligent 'roomware' in such facilities includes computer projection equipment, linked via high-speed connections to the internet, and teaching consoles with touch-pad controls that allow instructors to use and project audio and video tapes, show cable TV programmes and access computer applications from diskettes, CD-ROM, the internet and so on. Smart rooms also come with smart whiteboards, which not only show Web material, but also can be written on, or manipulated via touch to capture images, print them, etc. Students can download lecture notes directly from the whiteboard on to their laptops.

Use of these advanced facilities allowed me to integrate advanced multimedia presentation materials into lectures rather easily. Each semester, I lead students on internet 'safaris' to train them how to use economics websites most efficiently. I find that such 'hands-on' instruction works better, especially at the beginning of the semester, than passing out internet assignments.

Students have found the level of required interactivity challenging but instructive. In the online discussion area, I frequently post economics questions to which answers are due by the following class. Students work in groups, using the Web both to communicate with each other 
and to research the material. Each student has his or her own Web page to facilitate interactions with other students.

The Web has been of special importance in the service learning group projects that I assign each semester. In these projects, students are to offer substantial assistance to the community, and to learn something about an assigned economics topic in the process. In one semester, for instance, a group built a website to help the publicity and fundraising efforts of a community organisation serving the homeless. The group used their own group website (see http://groups.yahoo.com/) to communicate and build the community site, as well as to research key issues in urban poverty. A second group conducted a teach-in on campus on the economic costs of a potential war with Iraq, using the Web to research the topic.

I use the course website for announcements, to create quizzes and exams, to host discussions, maintain a grade book, etc. This has facilitated course management and reduced time spent in tutorials conducted in the office. With teaching assistants, I use the Web to monitor students' progress, to identify those in need of help and to assess whether they are grasping the material. We can drop in on group discussions, or view the results of individual interactive learning sessions. Such advantages are more important with larger courses.

I consider this multi-year experiment in Web pedagogy to be a success, and students have echoed those sentiments in course evaluations. Nevertheless, the added functionality of a Web course has, on balance, increased the amount of time I spend on my courses. Time was taken up in the early years by the steep learning curve, and even today links need to be updated and reviewed for continued relevance, economic headlines need to be brought to the attention of students, and new possibilities for Web-based learning need to be explored. Finally, I also utilise the Web in teaching graduate courses, but the approach is necessarily different. Naturally, there is less course management, but a greater need to help students learn how to conduct high-level research. I accomplished this goal by giving graduate students exclusive access to my research site, an economics research and learning portal that I maintain on an ongoing basis.

\section{Conclusion}

'Using the Web to teach' is a vague term, much like 'using books to teach'. Depending on your teaching approach, you might use the Web as an alternative distribution method for documents, a source of supplementary learning materials or an integrated environment for group collaboration. The academic community is still exploring the possibilities step by step (Hinde, 2003). The familiar process of hypothesis, experimentation and sharing results among peers is a long way from its final assessment of the usefulness of the Web for learning. We cannot say which level of Web use is appropriate for you and your students, but we can identify some factors to consider:

- The resources available. Some of the tools we have considered need technical support, even if only at the outset. However, even if you have zero technical assistance, you can set still set up a free blog or group using just your browser. The transition to online teaching is an opportunity to try a new teaching style, and this will take an investment of time and preparation.

- Your learning approach. We have seen that the Web enables new possibilities for active learning. For example, student groups can collaborate on a document and have their contributions monitored by the lecturer. 
- Your student audience. Part-timers, distance learners and others who have difficulty attending at arranged hours will benefit more from online documents and asynchronous online discussion. Students' access to and familiarity with computers are also factors to consider.

- The importance of transferable skills. Students may be looking to develop IT skills, online research skills or group working skills as part of their degree.

Bear in mind two strong drivers for use of the Web in higher education. One is the burden of greater class sizes. Online document sharing and online contact can potentially handle more student queries than office meetings. The other driver is student expectations. Students already use a search engine to satisfy their curiosity on all sorts of topics, and demand a high standard of online resources. They are so used to the idea of a virtual library that part of the teaching challenge will be to show them the value of the non-virtual library.

There is also a danger that lecturers will see the Web as a competitor for the library, neglecting its distinctive advantages. Rather than a collection of resources to be browsed, the Web is potentially a set of tools for research, self-assessment, discussion and experimentation. A page of equations can be a crucial part of learning economics, but the Web can connect you to an actual economic model and to perspectives on this week's economic issue.

\section{Where next?}

\subsection{Suggested reading}

The next sensible step is to consult your own institution's guidance on setting up a website. Advice on the available tools will be provided by the computing service, teaching support unit or learning technology unit. The following readings may also be helpful.

O'Leary, R. and Ramsden, A. (2002) 'Virtual Learning Environments', in P. Davies (ed.), The Handbook for Economics Lecturers: Teaching, Economics LTSN, Bristol, online at http://www.economicsnetwork.ac.uk/handbook/vle/ (last accessed 22 October 2004).

Poulter, M. L. (2002) Setting up an economics website: a beginner's guide', Computers in Higher Education Economics Review, vol. 15, no. 1, pp. 22-6, online at http://www.economicsnetwork.ac.uk/cheer/ch15_1/website.htm (last accessed 22 October 2004).

Simkins, S. P. (1999) 'Promoting active-student learning using the World Wide Web in economics courses', Journal of Economic Education, vol. 30, no. 3, pp. 278-91, online at http://www.indiana.edu/ econed/pdffiles/summer99/simkins.pdf (last accessed 2 February 2005).

\subsection{Key Web resources}

All links were last checked on 22 October 2004.

\section{Advice and guidance}

JISC Plagiarism Advisory Service, http://www.jiscpas.ac.uk/

Making Connections Unit (advice on accessible Web design), http://www.mcu.org.uk/

Web Accessibility Initiative (2003) 'WAI Quick Tips Reference Card', http://www.w3.org/WAI/References/QuickTips/ 


\section{Tools for site maintenance}

Economics Network Toolbox (create simple interactive features for your site, including multiple-choice questions and Prisoner's Dilemma games), http://www.economicsnetwork.ac.uk/teaching/toolbox.htm

Link Checker (software for Mac), http://www.dotsw.com/linkchecker.html Wayback Machine (archive of most of the Web), http://www.archive.org/

Xenu's Link Sleuth (Windows link-checker software), http://home.snafu.de/tilman/xenulink.html

\section{Tools for online discussion}

Blogger blogging service, http://Blogger.com/tour_start.g

Microsoft Network Groups, http://groups.msn.com/

Wiki Getting Started FAQ, http://c2.com/cgi/wiki?WikiGettingStartedFaq

Wordpress Blog software, http://wordpress.org/

Yahoo Groups, http://groups.yahoo.com/

\section{Resource guides (sites that help you find economics materials)}

Bized Internet catalogue, http://catalogue.bized.ac.uk/

Economics Network Links to Resources, http://www.economicsnetwork.ac.uk/links/

Economics Textbook Companion Sites, http://www.economicsnetwork.ac.uk/books/companions_t.htm

The Internet Economist, http://www.vts.rdn.ac.uk/tutorial/interneteconomist/

MERLOT (Multimedia Educational Resource for Learning and Online Teaching), http://www.merlot.org/artifact/BrowseArtifacts.po? catcode=353\&browsecat=339

Resources For Economists, http://netec.mcc.ac.uk/EconFAQ.html

What's New on Bized (e-mail newsletter), http://www.jiscmail.ac.uk/lists/bized-newsletter.html

\section{Some online materials created by economists}

J. Bradford DeLong's Semi-Daily Journal, http://www.j-bradford-delong.net/movable_type/

'Car Park Project' student activity at Glasgow Caledonian University, http://cbs3.gcal.ac.uk/eco/website/EME/EMECarParkProject.html

Economics 101 course site, Strathclyde University, http://homepages.strath.ac.uk/ hbs97102/econ101/

Eur Macro Tutor (interactive models and worksheets) http://www.fgn.unisg.ch/eurmacro/tutor/ Kevin Hinde's site, http://www.kevinhinde.com/

Journal of Economic Education online section, http://www.indiana.edu/ econed/onlinehome.htm Arnold Kling's Blog http://econlog.econlib.org/

Think Economics (Principles tutorials with interactive graphs), http://www.whitenova.com/thinkEconomics/

'Using the Internet' student activity at Glasgow Caledonian University, http://cbs3.gcal.ac.uk/eco/website/EME/EMEpresentation1a.html

The Virtual Economy (a UK macro model with illustrations of micro consequences), http://bized.ac.uk/virtual/economy/

\section{Notes}

1 Having said this, Blackboard in its current incarnation fails many accessibility challenges. 


\section{References}

All links were last checked on 22 October 2004.

Chizmar, J. F. and Walbert, M. S. (1999) 'Web-based learning environments guided by principles of good teaching practice', Journal of Economic Education, vol. 30, no. 3, pp. 248-64.

Daniel, J. I. (1999) 'Computer-aided instruction on the World Wide Web: the third generation', Journal of Economic Education, vol. 30, no. 2, pp. 163-74.

EDNER Project (2002a) 'Providing links to online resources for students', EDNER (Formative Evaluation of the Distributed National Electronic Resource) Project Issues Paper 4, online at http://www.cerlim.ac.uk/edner/ip/ip04.rtf

EDNER Project (2002b) 'Web accessibility issues for higher and further education', EDNER (Formative Evaluation of the Distributed National Electronic Resource) Project Issues Paper 6, online at http://www.cerlim.ac.uk/edner/ip/ip06.rtf

Gärtner, M. (2001) 'Intermediate macroeconomics tutorials and applets', Journal of Economic Education, vol. 32, no. 1, p. 93.

Hayward, B., Alty, C., Pearson, S. and Martin, C. (2003) 'Young people and ICT 2002: findings from a survey conducted in autumn 2002, Coventry: British Educational

Communications and Technology Agency, online at

http://www.becta.org.uk/page_documents/research/full_report.pdf

Heather, K. (2001) 'Case study: use of streamed video in economics lectures', Bristol: Economics LTSN, online at http://www.economicsnetwork.ac.uk/showcase/heather_streaming.htm

Hinde, K. (2003) 'Web-based learning and the student experience: reflections from a quasicyberspace practitioner', conference presentation at the Northumbria Conference 2003:

Educating for the Future, online at http://www.kevinhinde.com/Web-based\%20Learning\%20 and\%20the\%20student\%20experience.doc

Judge, G. (1999) 'The production and use of on-line Web quizzes for economics', Computers in Higher Education Economics Review, vol. 13, no. 1, pp. 21-5, online at http://www.economicsnetwork.ac.uk/cheer/ch13_1/ch13_1p21.htm

Kerkvliet, J. and Sigmund, C. L. (1999) 'Can we control cheating in the classroom?', Journal of Economic Education, vol. 30, no. 4, pp. 331-43.

Leidner, D. E. and Jarvenpaa, S. L. (1995) 'The use of information technology to enhance management school education: a theoretical view', MIS Quarterly, vol. 19, no. 3, Special Issue on IS Curricula and Pedagogy (September), pp. 266-91.

McConnell, C. R. and Brue, S. L. (2001) Macroeconomics, McGraw-Hill, Boston, MA.

Poulter, M. L. (1999) 'Designing for disabled users: principles and pitfalls of web site accessibility', Interact (University of Bristol Learning Technology Support Service) no. 22, pp. 10-11, online at http://www.ltss.bris.ac.uk/interact/22/Acrobat_22.pdf

Poulter, M. L. and Mitchell, C. J. (2001) 'The RDN Virtual Training Suite: information for teachers and trainers', online at http://www.vts.rdn.ac.uk/teachers/lecturer_handout.rtf

Seely Brown, J. (2001) 'Learning in the digital age', in M. Devlin, R. Larson and J. Meyerson (eds), The Internet and the University: Forum 2001, pp. 65-91, published as a joint project of the Forum for the Future of Higher Education and EDUCAUSE, 2002, online at http://www.johnseelybrown.com/learning_in_digital_age-aspen.pdf

Shirky, C. (2003) 'A group is its own worst enemy', online at http://www.shirky.com/writings/group_enemy.html

Web Accessibility Initiative (2003) 'Quick Tips to Make Accessible Web Sites', online at http://www.w3.org/WAl/References/Quicktips/ 


\section{Glossary}

blog: (from 'Web $\log ^{\prime}$ ') an online journal that is easy to update with short messages and links. The software takes care of generating pages and indexes from the various items that you 'blog'. browser: the software with Web pages are viewed. Internet Explorer dominates the market, but there are some good open source (q.v.) alternatives.

groupware: software that enables a group of users to collaborate by sharing messages and documents over a network. VLEs (q.v.) are examples of groupware.

HTML (HyperText Markup Language): the language in which Web pages are coded. These are essentially structured text documents that point to other pages using URLs (q.v.).

iChat: an Instant Messaging (q.v.) program for Apple computers.

IM (Instant Messaging): software that tells the user when friends are online and enables them to chat in real time.

linkrot: if a list of links is not maintained, its usefulness will erode as the linked sites move, disappear or update their content so that it is no longer relevant. Section 3.1 discusses how to combat this process.

lurking: reading the contributions to a virtual community (q.v.) without actively participating. It is usually good etiquette to lurk in a community for a while before contributing.

MSN Messenger: a popular Instant Messaging (q.v.) program created by the MicroSoft Network. open source: the underlying code of some software is published and reviewed in a manner analogous to academic research. It is added to the public commons rather than kept as a proprietary secret. These "open source" programs often cost nothing, yet are superior in many respects because they can be scrutinised and customised by other programmers. There are open source programs for just about any application, including browsers (q.v.) and groupware (q.v.). plug-in: a piece of software that works with a browser (q.v.) to allow users to view resources such as interactive tutorials or video. Being able to view an interactive online resource is a matter of having the right plug-ins.

social software: software, running on an individual's computer or on a website, with which users can create personal profiles, form groups and exchange messages. They can also 'rate' each other and so build reputations.

streaming: most files have to be downloaded from the Web before they can be viewed. Some files such as video lectures play while they are loading, which saves time. This is called streaming. thread: some discussion forums present the messages chronologically, without respect for topic, but others show them linked by topic, each contribution appearing underneath the message it is responding to. This is called 'threading' and a debate on a particular topic is called a thread.

URL (uniform resource locator): the address of a particular file on the Web, which works from any part of the internet. An example is http://www.google.com/options/.

virtual community: a group of people communicating over a network on a shared interest, possibly via a moderator. This might be through an e-mail list, an online discussion board, a chat room or social software (q.v.).

VLE (Virtual Learning Environment): a package to help lecturers create a course website with a minimum of technical skill, including tools for discussion and document sharing.

Web log: see Blog.

wiki: a wiki is a website that visitors can edit using their browser. Groups can use a wiki to author documents collaboratively. An example is Wikipedia.org, the collaborative encyclopaedia.

Yahoo Messenger: a very popular Instant Messaging (q.v.) program, also known as 'YIM'. 